\title{
Proteomic analysis of the effect of the polyphenol pentagalloyl glucose on proteins involved in neurodegenerative diseases in activated BV-2 microglial cells
}

\author{
PATRICIA MENDONCA, EQUAR TAKA and KARAM F. A. SOLIMAN \\ College of Pharmacy and Pharmaceutical Sciences, Florida A\&M University, Tallahassee, FL 32307, USA
}

Received October 26, 2018; Accepted May 9, 2019

DOI: $10.3892 / \mathrm{mmr} .2019 .10400$

\begin{abstract}
Neuroinflammation and microglial activation are two important hallmarks of neurodegenerative diseases. Continuous microglial activation may cause the release of several cytotoxic molecules, including many cytokines that are involved in the inflammatory process. Therefore, attenuating inflammation caused by activated microglia may be an approach for the therapeutic management of neurodegenerative diseases. In addition, many studies have reported that polyphenol pentagalloyl glucose $(1,2,3,4,6$-penta-O-galloyl- $\beta$ D-glucose; PGG) is a molecule with potent anti-inflammatory effects, such as inhibiting the release of proinflammatory cytokines. Our previous studies revealed that PGG attenuated the expression of two inflammatory cytokines (murine monocyte chemoattractant protein-5 and pro-metalloproteinase-9) in lipopolysaccharide/interferon $\gamma$-activated BV-2 microglial cells. Additionally, PGG modulated the NF- $\kappa$ B and MAPK signaling pathways by altering genes and proteins, which may affect the MAPK cascade and $\mathrm{NF}-\kappa \mathrm{B}$ activation. The aim of the present study was to investigate the ability of PGG to
\end{abstract}

Correspondence to: Dr Karam F. A. Soliman, College of Pharmacy and Pharmaceutical Sciences, Florida A\&M University, Room 104 Dyson Pharmacy Building, 1520 ML King Boulevard, Tallahassee, FL 32307, USA

E-mail: karam.soliman@famu.edu

Abbreviations: A $\beta$, amyloid- $\beta$; AD, Alzheimer's disease; ADSS, adenylosuccinate synthetase isozyme 2; ALS, amyotrophic lateral sclerosis; CNS, central nervous system; IFN $\gamma$, interferon $\gamma$; FASP, Filter Aided Sample Preparation; GA, gallic acid; GLOD4, Glyoxalase 4; LPS, lipopolysaccharide; MAPK, mitogen-activated protein kinase; MCP-5, monocyte chemoattractant protein-5; NCBI, National Center for Biotechnology Information; NF- $\kappa \mathrm{B}$, nuclear factor- $\kappa \mathrm{B}$; PANTHER, Protein Analysis Through Evolutionary Relationships; PD, Parkinson's disease; PGG, 1,2,3,4,6-penta-Ogalloyl- $\beta$-D-glucose; Pro MMP-9, pro-metalloproteinase-9; SCA2, spinocerebellar ataxia type 2; TLR4, Toll-like receptor 4; WIPF1, WAS/WASL-interacting protein family member 1

Key words: PGG, microglia, neurodegeneration, septin-7, Ataxin-2, ADSS modulate the expression of proteins released in activated BV-2 microglial cells, which may be involved in the pathological process of inflammation and neurodegeneration. Proteomic analysis of activated BV-2 cells identified 17 proteins whose expression levels were significantly downregulated by PGG, including septin-7, ataxin-2, and adenylosuccinate synthetase isozyme 2 (ADSS). These proteins were previously described as being highly expressed in neurodegenerative diseases and/or involved in the signaling pathways associated with the formation and growth of neuronal connections and the control of Alzheimer's disease pathogenesis. The inhibitory effect of PGG on ataxin-2, septin-7 and ADSS was further confirmed at the protein and transcriptional levels. Therefore, the obtained results suggest that $\mathrm{PGG}$, with its potent inhibitory effects on ataxin-2, septin-7 and ADSS, may have potential use in the therapeutic management of neurodegenerative diseases.

\section{Introduction}

Microglia represent immune cells of the central nervous system (CNS) and are the main cells responsible for the intrinsic brain immune system $(1,2)$. Under normal conditions, microglia monitor the surroundings continuously to identify the presence of CNS injury or damage, and they seem to preserve homeostasis through several interactions with neurons. However, continuous microglial activation increases the release of proinflammatory cytokines (1), which may cause detrimental inflammatory effects (3). This chronic inflammatory process enlists effector cells and can create a feedback loop, perpetuating inflammation and finally damaging the neurons $(4,5)$. Microglial production of cytokines occurs as a response to injury, trauma or infection (6). Thus, the chronic activation of microglia is a critically important step in the development of neurodegeneration, leading to neuronal malfunction or complete neuron disability (1).

The knowledge of the detrimental effects caused by inflammation in the development of neurodegeneration shows that reducing inflammation may assist in delaying disease advancement. Compounds that can modulate microglial activity and decrease inflammation to controllable levels could be beneficial for neuronal survival (7). Moreover, the role of neuroinflammation in Alzheimer's disease (AD) progression was previously reported, showing the effects of NSAIDs on AD progression $(8,9)$. Furthermore, several AD 
models were used to demonstrate the neuroprotective effects of different compounds with anti-inflammatory potential (10). Consequently, attenuating inflammatory mediators can help reduce or retard the advancement of AD.

Various compounds extracted from plants have shown strong anti-inflammatory activity. The polyphenol pentagalloyl glucose (1,2,3,4,6-penta-O-galloyl- $\beta$-D-glucose, PGG) is found in many medicinal plants, including Rhus chinensis Mill and Paeonia suffruticosa $(5,11)$. This compound has been reported in several in vivo and in vitro studies showing its potential in the therapy and prevention of several inflammatory diseases. Our earlier work showed that PGG inhibited the release of MCP-5 (monocyte chemoattractant protein-5) and pro-MMP-9 (pro-metalloproteinase-9) in activated BV-2 cells (12). PGG also modulated genes and proteins involved in the nuclear-factor- $\kappa \mathrm{B}(\mathrm{NF}-\kappa \mathrm{B})$ and mitogen-activated protein kinase (MAPK) signaling pathways, which may affect the MAPK cascade, NF- $\kappa \mathrm{B}$ activation, and the subsequent release of MCP-5 and pro-MMP-9 (13). The current work investigated the effect of PGG on the expression of proteins that may be involved in the pathogenesis of neuroinflammation and neurodegenerative diseases using an LPS/IFN $\gamma$-activated BV-2 microglial cell model.

\section{Materials and methods}

Chemicals and reagents. Polyphenol pentagalloyl glucose (1,2,3,4,6-penta-O-galloyl- $\beta$-D-glucose-purity 96.8\%), bovine serum albumin (BSA), dimethyl sulfoxide (DMSO), lipopolysaccharide from Salmonella enterica (LPS), interferon $\gamma(\mathrm{IFN} \gamma)$, urea, Tris $/ \mathrm{HCl}$, iodoacetamide, trypsin, $\mathrm{NaCl}$, trifluoracetic acid $\left(\mathrm{CF}_{3} \mathrm{COOH}\right)$, ammonium bicarbonate $\left(\mathrm{NH}_{4} \mathrm{HCO}_{3}\right)$, and general chemicals were purchased from Sigma-Aldrich Co. and VWR International. Dulbecco's modified Eagle's medium-high glucose medium (DMEM), penicillin/streptomycin, fetal bovine serum heat inactivated (FBS-HI), trypsin-EDTA, and Hank's Balanced Salt Solution (HBSS) were purchased from Genesee Scientific. All reagents and plates for western blot assays were purchased from ProteinSimple. Bradford reagent, PCR primers, and reagents were from Bio-Rad, and primary antibodies were from Thermo Fisher Scientific (Table I).

Cell culture and treatments. The immortalized murine microglial BV-2 cell line was provided by Dr Elizabetta Blasi (14). Cells were grown in T-75 flasks using DMEM supplemented with $10 \%$ heat-inactivated FBS and $1 \%$ penicillin $(100 \mathrm{U} / \mathrm{ml}) /$ streptomycin $(0.1 \mathrm{mg} / \mathrm{ml})$ in an incubator set for $5 \% \mathrm{CO}_{2}$. at $37^{\circ} \mathrm{C}$. For the experimental media, only $2.5 \%$ of heat-inactivated FBS was added. LPS and IFN $\gamma$ were stored at $-20^{\circ} \mathrm{C}$ at concentrations of $1 \mathrm{mg} / \mathrm{ml}$ and $200 \mathrm{ng} / \mathrm{ml}$, respectively. The working concentrations of $0.2 \mu \mathrm{g} / \mathrm{ml}$ and $0.2 \mathrm{ng} / \mathrm{ml}$ were then used in the experiments. DMSO was used to dissolve PGG, and the final concentration of DMSO did not exceed $0.1 \%$ (15). The selected concentration of PGG was based on the cell viability results from our prior study (12), which showed $>80 \%$ of viable cells after treatment with $25 \mu \mathrm{M}$ PGG. The count of cells in all the experiments was $5 \times 10^{5} / \mathrm{ml}$, and the treatments consisted of the control (DMSO), PGG, LPS/IFN $\gamma$, and PGG followed by the combination of LPS/IFN $\gamma$ after $1 \mathrm{~h}$.
Proteomic assay. In this experiment, BV-2 cells were plated in experimental media and incubated overnight. The next day, the cells were treated as described before. After $24 \mathrm{~h}$, cells were harvested using $0.25 \%$ trypsin-EDTA by first aspirating the medium, centrifuging, and washing the cells twice with PBS. Once the pellet was ready, using the Filter Aided Sample Preparation (FASP) protocol, samples were prepared by mixing $30 \mu \mathrm{l}$ of cell lysate with $200 \mu \mathrm{l}$ of UA (8 $\mathrm{M}$ urea in $0.1 \mathrm{M}$ Tris $/ \mathrm{HCl} \mathrm{pH} \mathrm{8.5)} \mathrm{in} \mathrm{the} \mathrm{filter} \mathrm{unit} \mathrm{and}$ centrifuged twice. The flow through from the collection tube was discarded. Then, $100 \mu \mathrm{l}$ of IAA $(0.05 \mathrm{M}$ iodoacetamide in UA) solution was added and mixed at $600 \mathrm{rpm}$ in a thermomixer for $1 \mathrm{~min}$ and incubated without mixing for $20 \mathrm{~min}$. After centrifuging, $100 \mu \mathrm{l}$ of UA was added to the filter unit and centrifuged. Next, $100 \mu \mathrm{l}$ of $\mathrm{ABC}\left(0.05 \mathrm{M} \mathrm{NH}_{4} \mathrm{HCO}_{3}\right.$ in water) was added to the filter unit and centrifuged. Then, $40 \mu \mathrm{l}$ $\mathrm{ABC}$ with trypsin (enzyme to protein ratio 1:100) was added and mixed at $600 \mathrm{rpm}$ in a thermomixer for $1 \mathrm{~min}$. The units were incubated at $37^{\circ} \mathrm{C}$ for $18 \mathrm{~h}$, and the filter units were transferred to new collection tubes. Then, $50 \mu \mathrm{l}$ of $\mathrm{NaCl}(0.5 \mathrm{M})$ was pipetted into the filter and centrifuged. Using $\mathrm{CF}_{3} \mathrm{COOH}$, the filtrate was acidified, desalted and sent to the Translational Science Laboratory for Orbitrap/QExactive Proteomic LC-MS/MS (liquid chromatography-mass spectrometry) for complex mixture analysis. Using 'Scaffold version 4.4' software, the results were then analyzed, and the fold change of each protein of interest was calculated.

Protein assay. Cells were appropriately treated and kept in the incubator for $24 \mathrm{~h}$. The next day, cells were harvested, washed twice with PBS, and lysed with buffer containing protease inhibitor cocktail. Using Bradford reagent, the concentration of protein was measured. Five $\mu l$ of standards in concentrations of 0 to $2 \mathrm{mg} / \mathrm{ml}$ or $5 \mu \mathrm{l}$ of samples and $200 \mu \mathrm{l}$ of protein assay reagent were added to the 96-well plate. Using a Synergy HTX Multi-Reader (BioTek), the concentration of proteins was measured at $595 \mathrm{~nm}$ wavelength.

Capillary electrophoresis western blot analysis. Total protein expression was determined using western blot analysis (Wes, ProteinSimple). The protein concentration was determined as described above. ProteinSimple provided the reagents and protocol for the assay. The concentrations of antibody and protein for the experiments were first optimized by being tested at 3 different concentrations. The best concentration was then selected for further tests. Briefly, the protein samples (concentration: $0.2 \mathrm{mg} / \mathrm{ml}$ ) were mixed with sample buffer, fluorescent molecular weight markers, and dithiothreitol and left in a heat block at $95^{\circ} \mathrm{C}$ for $5 \mathrm{~min}$. The microplate provided with the kit was then loaded with blocking buffer, antibodies (in dilutions ranging from 1:5 to 1:25), secondary antibody, chemiluminescent substrate, separation and stacking matrices. The microplate was then placed in the instrument and through the capillary system; the electrophoresis and immunodetection occurred. The reaction identifies specific proteins by using primary and secondary antibodies and a chemiluminescent substrate. The Wes instrument provided us with real-time results of the experiment. By using a charge-coupled device camera, the chemiluminescence reaction and the digital image were analyzed by the software (ProteinSimple Compass). 
Table I. List of primary antibodies.

\begin{tabular}{lllll}
\hline Antibody & Catalog no. & Type & Species reactivity & Host/Isotype \\
\hline Septin-7 & PA5-56181 & Polyclonal & human, mouse, rat & Rabbit/IgG \\
Ataxin-2 & PA5-54336 & Polyclonal & human, mouse, rat & Rabbit/IgG \\
ADSS & PA5-55070 & Polyclonal & human, mouse, rat & Rabbit/IgG \\
\hline
\end{tabular}

All antibodies were purchased from Thermo Fisher Scientific, Inc. IgG, immunoglobulin G; ADSS, adenylosuccinate synthetase isozyme 2.

Reverse transcriptase-polymerase chain reaction ( $R T-q P C R$ ) $R N A$ extraction and cDNA synthesis. Cell pellets from the different treatments were initially lysed with $1 \mathrm{ml}$ of TRIzol reagent. Chloroform $(0.2 \mathrm{ml})$ was added, vortexed, incubated at $15-30^{\circ} \mathrm{C}$ for $2-3 \mathrm{~min}$, and centrifuged at $10,000 \mathrm{~g}$ for $15 \mathrm{~min}$ at $2-8^{\circ} \mathrm{C}$. The aqueous phase of the lysed samples was transferred to a fresh tube, and the RNA was precipitated by mixing with isopropyl alcohol $(0.5 \mathrm{ml})$. After centrifugation, $75 \%$ ethanol was used to wash the RNA pellet. After centrifugation at $7,500 \mathrm{~g}$ for $5 \mathrm{~min}$ at $2-8^{\circ} \mathrm{C}$, the pellet was left to dry for $15 \mathrm{~min}$ and then dissolved in water (RNase free). The purity and RNA concentration were measured using a NanoDrop (Thermo Fischer Scientific). Using iScript advanced reverse transcriptase from Bio-Rad, the cDNA strands were synthesized based on the mRNA. The solutions were loaded into $0.2 \mathrm{ml}$ tubes and included $5 \mathrm{X}$ iScript advanced reaction mix (4 $4 \mathrm{l})$ (containing primers), reverse transcriptase $(1 \mu \mathrm{l})$, sample $(1.5 \mu \mathrm{g} / 7.5 \mu \mathrm{l})$, and water $(7.5 \mu \mathrm{l})$ in a total of $20 \mu \mathrm{l}$. The thermal cycling for reverse transcription steps included $30 \mathrm{~min}$ at $42^{\circ} \mathrm{C}$ and $5 \mathrm{~min}$ at $85^{\circ} \mathrm{C}$.

$R T-P C R$. PCR amplification followed the Bio-Rad protocol. A $1 \mu \mathrm{l}$ aliquot of the sample (200 ng cDNA/reaction), $10 \mu \mathrm{l}$ of SsoAdvanced ${ }^{\mathrm{TM}}$ Universal SYBR $^{\circledR}$-Green Supermix (Bio-Rad), $1 \mu \mathrm{l}$ of primer, and $8 \mu \mathrm{l}$ of water were pipetted into each well. Using the CFX96 Real-Time System from Bio-Rad, the protocol provided by the company was followed: Initial $95^{\circ} \mathrm{C}$ for $2 \mathrm{~min}$ (hold step) and $95^{\circ} \mathrm{C}$ for $15 \mathrm{sec}$ (denaturation), followed by 40 cycles of $60^{\circ} \mathrm{C}$ for $30 \mathrm{sec}$ (annealing/extension) and $65-95^{\circ} \mathrm{C}$ for $5 \mathrm{sec} / \mathrm{step}$ (melting curve). Primers were selected according to the specific genes of interest. The identification of each primer was provided by the manufacturer (Bio-Rad).

- Septin-7-UniqueAssayID: qMmuCID0017359

- Ataxin-2-UniqueAssayID: qMmuCID0025396

- ADSS-UniqueAssayID: qMmuCID0005512

\section{Data analysis}

Statistical analysis. Statistical analysis of the obtained results included a minimum of 3 biological replicates and 3 technical replicates for each one of the assays. For the proteomics assay, data analysis was performed using Scaffold software, and the significance of the difference between the groups was assessed using Student's t-test $(\mathrm{P}<0.05)$. The results from the western blot assay were analyzed using ProteinSimple Compass software from the manufacturer. For the RT-PCR assays, Bio-Rad CFX manager software was used. The software automatically calculates the differences in mRNA expression for each of the treatments compared to the reference gene (GAPDH). All data are expressed as the mean \pm standard error of the mean, and the significance of the difference between the groups was assessed using a one-way analysis of variance, followed by Dunnett's multiple comparison post hoc tests. $\mathrm{P}<0.05$ was considered to indicate a statistically significant difference.

Bioinformatics analysis. The NCBI (National Center for Biotechnology Information-ncbi.nlm.nih.gov) (16) and PANTHER (Protein Analysis Through Evolutionary Relationships-pantherdb.org) (17) databases were used to identify biological and molecular functions, as well as signaling pathways associated with the proteins.

\section{Results}

A proteomic approach was used to profile the effect of PGG on global protein expression in LPS/IFN $\gamma$-activated BV-2 microglia cells. A total of 1895 proteins were identified as being differentially expressed after cells were treated with PGG, LPS/IFN $\gamma$ or the combinations of PGG + LPS/IFN $\gamma$. Among those, specific proteins were selected according to the fold change. Proteins with at least a 7 -fold change in inhibition after PGG treatment were chosen, resulting in a total of 24 proteins. Then, statistical analysis was used to select those that showed significant inhibition after PGG treatment. A total of 17 proteins were identified for further studies, as shown in the volcano plot (Fig. 1). The fold change was calculated by comparing the control vs. LPS/IFN $\gamma$ groups (Table II) and the LPS/IFN $\gamma$ vs. PGG + LPS/IFN $\gamma$ groups (Table III). The data obtained show that even for those proteins where LPS/IFN $\gamma$ did not induce an augmentation in protein expression, PGG pretreatment downregulated their expression up to 53-fold (Tables II and III). Some of these highly downregulated proteins are known to be involved in cancer progression.

Annotation of the function of the different proteins was performed using the NCBI data file to identify the biological relevance of the differentially expressed proteins in response to PGG treatment. The proteins were placed into 15 biological processes (biological regulations, cellular and developmental processes, establishment of localization, growth, localization, locomotion, metabolic process, multi-organism and multicellular organism processes, reproduction, reproductive process, response to stimulus, rhythmic process and viral reproduction) (Fig. 2) and 5 molecular functions (binding, catalytic activity, molecular function, transcription regulator activity, and transporter activity).

The PANTHER classification system was used to classify the proteins according to the signaling pathway that they are 
Table II. Effect of LPS/IFN $\gamma$ on the protein expression of BV-2 cells.

\begin{tabular}{|c|c|c|c|c|}
\hline Protein name & Protein ID & $\begin{array}{c}\text { Molecular } \\
\text { weight, kDa }\end{array}$ & $\begin{array}{l}\text { P-value } \\
\text { (t-test) }\end{array}$ & $\begin{array}{c}\text { Fold } \\
\text { change }\end{array}$ \\
\hline Ataxin-2-like protein & ATX2L & 111 & 0.047 & +3 \\
\hline Septin-7 & SEPT7 & 51 & 0.011 & +2 \\
\hline SNW domain-containing protein & SNW1 & 61 & 0.048 & +5 \\
\hline WAS/WAS/L-interacting protein & WIPF1 & 50 & 0.050 & 1 \\
\hline Thymidylate synthase & TYSY & 35 & $<0.00010$ & 1 \\
\hline Acidic leucine-rich nuclear phosphoprotein 32 family member & AN32B & 31 & 0.011 & 1 \\
\hline $5^{\prime}-3^{\prime}$ exoribonuclease 2 & XRN2 & 109 & 0.0018 & 1 \\
\hline Protein-L-isoaspartate (D-aspartate) O-methyltransferase & PIMT & 25 & 0.0036 & 1 \\
\hline Puromycin-sensitive aminopeptidase & PSA & 103 & $<0.00014$ & +3.4 \\
\hline Coronin-1B & COR1B & 54 & 0.017 & 1 \\
\hline Bleomycin hydrolase & BLMH & 53 & 0.040 & +1.6 \\
\hline Emerin & EMD & 29 & 0.013 & +1.7 \\
\hline Nuclear transport factor 2 & NTF2 & 14 & $<0.00095$ & 1 \\
\hline Treacle protein & TCOF & 135 & $<0.00098$ & 1 \\
\hline Adenylosuccinate synthetase isozyme 2 & PURA2 & 50 & $<0.00010$ & 1 \\
\hline Protein phosphatase & PPM1G & 59 & $<0.00010$ & 1 \\
\hline Glyoxalase domain-containing protein 4 & GLOD4 & 33 & $<0.00010$ & +3.2 \\
\hline
\end{tabular}

Table of the proteins identified by Orbitrap/QExactive Proteomic LC-MS/MS and the respective molecular weight. The fold change corresponds to the increase in the protein expression when BV-2 cells were activated by LPS/IFN $\gamma$, tested in three independent studies ( $\mathrm{n}=3$ ). Statistically significant differences between control and LPS/IFN $\gamma$ were evaluated by a Student's t-test, $\mathrm{P}<0.05$.

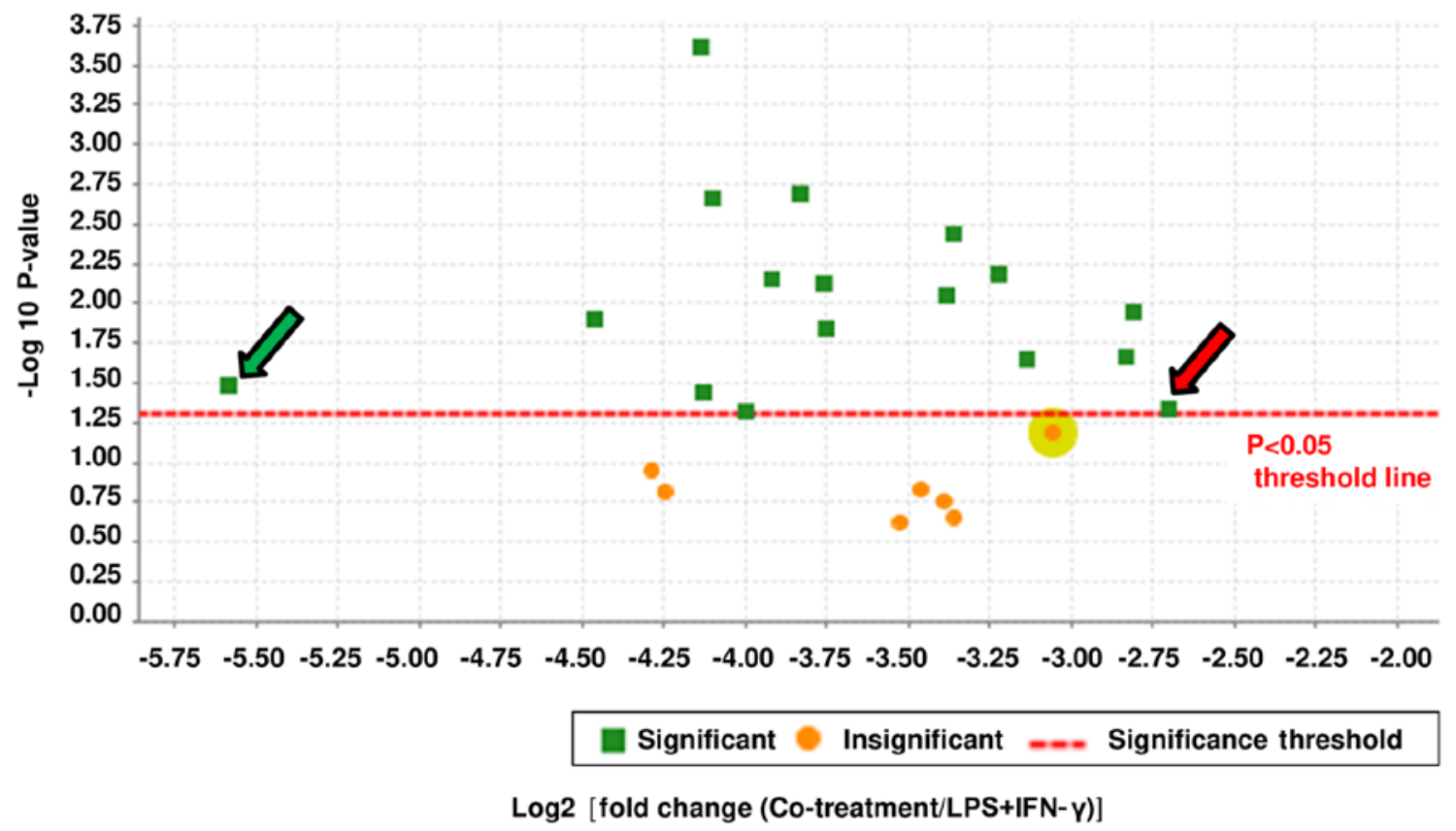

Figure 1. Volcano plot of fold changes of proteins affected by PGG treatment. The red line represents the statistical significance threshold line at P<0.05. Green and orange dots represent proteins and the level of expression. Orange dots represent fold changes that were not statistically significant. Green and red arrows indicate the proteins with the highest and lowest fold change after PGG treatment, respectively ( $\mathrm{n}=3$ ). The plot was obtained with Scaffold version 4.4 software.

associated with. The database found that 3 proteins (adenylosuccinate synthase isozyme 2 (ADSS), thymidylate synthase, and 5'-3' exoribonuclease) were involved in 6 signaling pathways: DNA replication, de novo purine biosynthesis, de novo pyrimidine deoxyribonucleotide biosynthesis, formyltetrahydrofolate biosynthesis, tetrahydroformate biosynthesis, and the Wnt signaling pathway.

Among the 17 proteins significantly downregulated by PGG, septin-7, ataxin-2 and ADSS were of special interest because these proteins were previously described as being 
Table III. Effect of PGG on LPS/IFN $\gamma$-activated BV-2 Cells

\begin{tabular}{|c|c|c|c|c|}
\hline Protein name & Protein ID & $\begin{array}{c}\text { Molecular } \\
\text { weight, kDa }\end{array}$ & $\begin{array}{l}\text { P-value } \\
\text { (t-Test) }\end{array}$ & $\begin{array}{c}\text { Fold } \\
\text { change }\end{array}$ \\
\hline Ataxin-2-like protein & ATX2L & 111 & 0.015 & -7.2 \\
\hline Septin-7 & SEPT7 & 51 & 0.017 & -8 \\
\hline SNW domain-containing protein & SNW1 & 61 & 0.048 & -8.4 \\
\hline WAS/WAS/L-interacting protein & WIPF1 & 50 & 0.022 & -9.4 \\
\hline Thymidylate synthase & TYSY & 35 & 0.01 & -9.7 \\
\hline Acidic leucine-rich nuclearphosphoprotein & AN32B & 31 & 0.025 & -10 \\
\hline \multicolumn{5}{|l|}{32 family member } \\
\hline $5^{\prime}-3^{\prime}$ exoribonuclease 2 & XRN2 & 109 & 0.015 & -14 \\
\hline Protein-L-isoaspartate (D-aspartate) O-methyltransferase & PIMT & 25 & 0.0013 & -14 \\
\hline Puromycin-sensitive aminopeptidase & PSA & 103 & 0.008 & -15 \\
\hline Coronin-1B & COR1B & 54 & 0.029 & -16 \\
\hline Bleomycin hydrolase & BLMH & 53 & 0.0089 & -17 \\
\hline Emerin & EMD & 29 & 0.046 & -18 \\
\hline Nuclear transport factor 2 & NTF2 & 14 & 0.0075 & -20 \\
\hline Treacle protein & TCOF & 135 & 0.012 & -23 \\
\hline Adenylosuccinate synthetase isozyme 2 & PURA2 & 50 & 0.0028 & -23 \\
\hline Protein phosphatase & PPM1G & 59 & 0.041 & -30 \\
\hline Glyoxalase domain-containing protein 4 & GLOD4 & 33 & 0.022 & -53 \\
\hline
\end{tabular}

Table of proteins identified by Orbitrap/QExactive Proteomic LC-MS/MS and the respective molecular weight. The fold change corresponds to the inhibition of the protein expression when activated BV-2 cells were pre-treated with PGG, tested in three independent studies ( $\mathrm{n}=3$ ). Statistically significant differences between LPS/IFN $\gamma$ and PGG + LPS/IFN $\gamma$ were evaluated by a Student's t-test, $\mathrm{P}<0.05$.

highly expressed in neurodegenerative diseases and/or involved in the development of neuronal circuits and control of AD and Parkinson's disease (PD) pathogenesis. To validate the proteomic results, we performed western blot assays with specific antibodies against Septin-7, Ataxin-2 and ADSS. The results showed that LPS/IFN $\gamma$ induced the expression of these proteins in BV-2 microglial cells and significantly reduced their expression when activated BV-2 microglial cells were pretreated with PGG (Figs. 3-5).

In this investigation, to confirm whether the changes observed in protein expression were the result of transcriptional regulation, we used RT-PCR to determine the mRNA levels of the three proteins studied. The RT-PCR assay results were consistent with the results obtained from the proteomics and western blot assays. PGG significantly suppressed the expression of the ataxin-2, septin-7 and ADSS genes (Fig. 6A-C). Therefore, these results confirmed the inhibitory effect of PGG on related proteins and genes involved in neurodegeneration.

\section{Discussion}

Neuroinflammation is a prominent trait common to many neurodegenerative diseases (7), such as AD, PD, and several other disorders, such as amyotrophic lateral sclerosis, multiple sclerosis, spinal cord injury, and traumatic brain (18). Persistent activation of innate immunity, including responses mediated by microglial activation, is a common association among these diseases, causing activation of neurotoxic pathways that may lead to progressive neurodegeneration (18).

The current study indicates that PGG has profound effects on the proteome, causing up to a 53-fold inhibition of protein expression. PGG has proven to be a very potent antioxidant agent $(19,20)$. While gallic acid (GA) is the primary product of tannic acid hydrolysis (21), PGG showed higher antioxidant activity (22). Moreover, oral PGG was found to reduce the accumulation of human amyloid $\beta(A \beta)$ protein in the brains of transgenic mice overexpressing this protein (23). PGG inhibited accumulation at doses more than 10 times lower than that of the plant extract. The study showed that PGG suppresses A $\beta$ fibril accumulation in treated animals, implying that PGG treatment could offer a therapeutic aid for AD patients with moderate cognitive injury (23). Additionally, by applying the combined technology of ion mobility associated with mass spectrometry, transmission electron microscopy, and molecular kinetics, studies indicated that PGG interacts with the $\mathrm{N}$-terminal metal binding segment and the first central hydrophobic core, interfering with $A \beta_{1-40}$ and $A \beta_{1-42}$ amyloid assembly. These results showed that $\mathrm{PGG}$ is a potential therapeutic drug to mitigate A $\beta$ oligomer neurotoxicity (24).

Currently, there are many cell models used to examine neuroinflammation, including primary microglial cultures and immortalized microglial cell cultures (25). In the present work, we used BV-2 microglial cells that showed similar properties to primary microglia $(2,25)$. Henn et al $(2)$ showed that in response to LPS, $90 \%$ of genes induced in BV-2 cells 

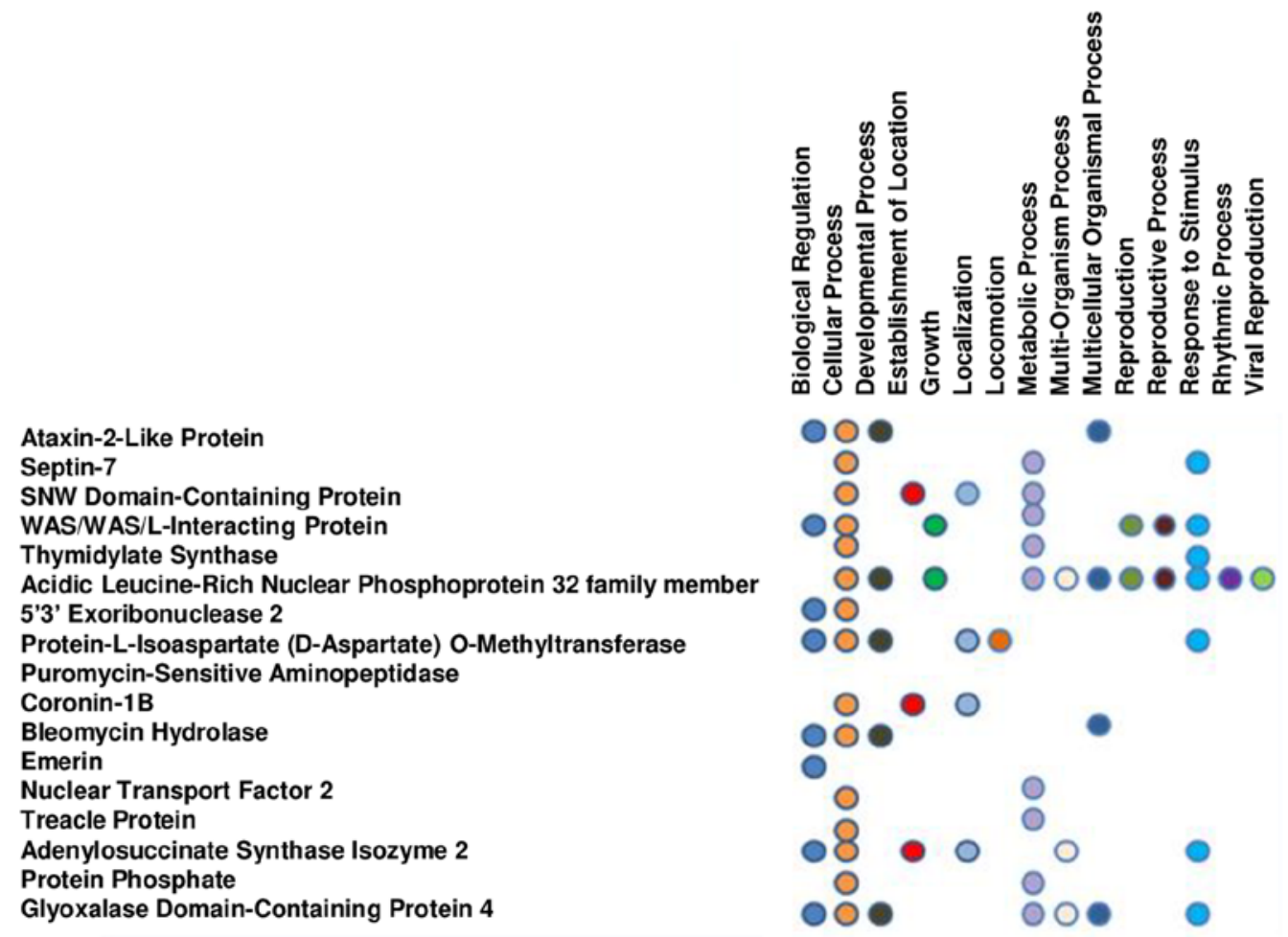

Figure 2. Gene Ontology annotation. Presents the biological processes of 17 differentially expressed proteins identified and quantified by the Orbitrap/QExactive liquid chromatography-MS/MS technique and analyzed by Scaffold version 4.4 software. PPG, polyphenol pentagalloyl glucose (1,2,3,4,6-penta-O-galloyl- $\beta$-D-glucose); MS, mass spectrometry.

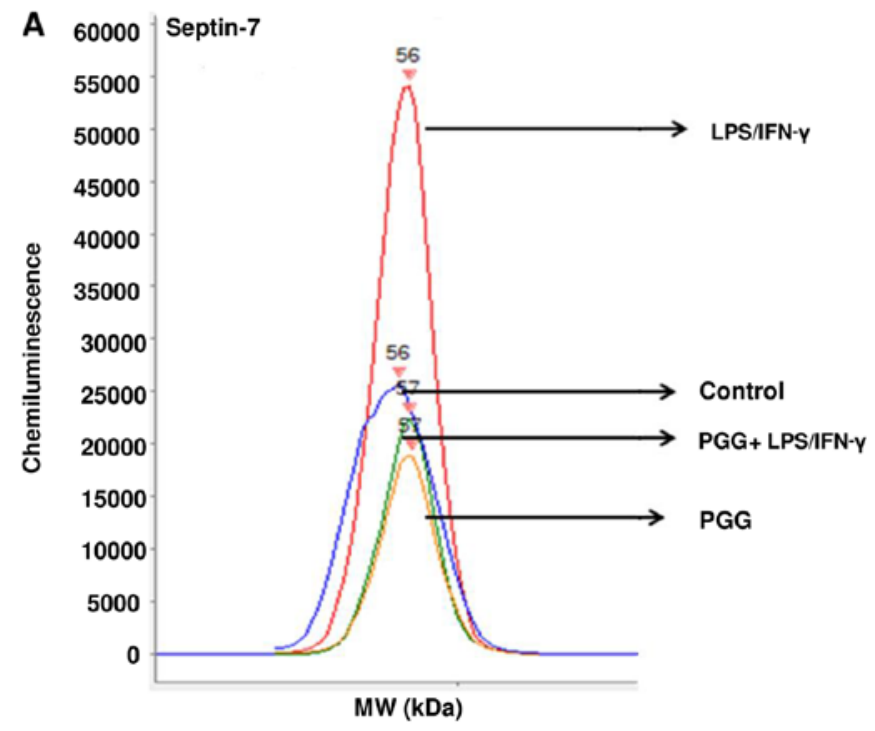

B

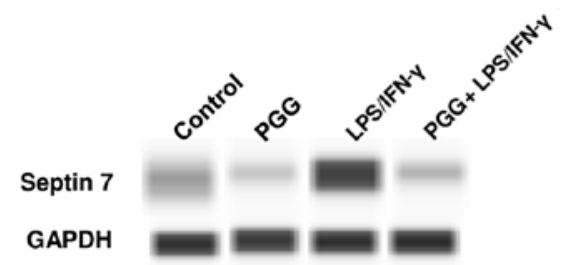

Figure 3. Effect of PGG on the expression of septin-7 as determined by western analysis with automated capillary electrophoresis. (A) Graph of the amount of chemiluminescence measured in the different treatments. (B) Bands representing the protein expression in control (DMSO), PGG $(25 \mu \mathrm{M}), \mathrm{LPS} / \mathrm{IFN} \gamma$, and pretreated cells (PGG $+\mathrm{LPS} / \mathrm{IFN} \gamma)$ after $24 \mathrm{~h}$ of treatment $(\mathrm{n}=3)$. PPG, polyphenol pentagalloyl glucose $(1,2,3,4,6$-penta-Ogalloyl- $\beta$-D-glucose); LPS, lipopolysaccharide; IFN $\gamma$, interferon $\gamma$. were also induced in primary microglia; however, the upregulation of genes in BV-2 was less pronounced. Although BV-2 cells have an inflammatory response that is not identical to primary cultures, they are still an important and widely used cell model for neuroinflammation. Our prior studies showed that PGG inhibited the expression of MCP-5 and pro-MMP-9 in LPS/IFN $\gamma$-activated BV-2 microglial cells. These proinflammatory cytokines may have a connection with the development of neurofibrillary tangles and senile plaques in AD patients. Our earlier studies also showed that PGG can modulate genes that participate in NF- $\kappa \mathrm{B}$ and MAPK signaling, which are key components in the process of neuroinflammation. PGG modulated the expression of CDK2, CHUK, IRAK1 and NF- $\mathrm{NB} 1$ at the transcriptional and protein levels, which may help to explain how PGG downregulates the release of MCP-5 and pro-MMP-9 in stimulated BV-2 microglial cells $(12,13)$.

In the present study, the data obtained indicate that PGG was very effective at inhibiting the expression of proteins and genes that are critical to neurodegeneration, including septin-7, ataxin-2 and ADSS. These proteins have been found to be involved in the pathogenesis of neurodegenerative diseases. Kinoshita and colleagues reported that septins were concentrated in the brains of AD patients, specifically in the intracellular neurofibrillary tangles, dystrophic neurites in senile plaques, and neuropil threads (26). Septins were shown to be involved in neurodegeneration and neurobehavioral conditions. Reports have shown that the septin family is found in postsynaptic densities when analyzed by mass spectrometry $(27,28)$, indicating a possible involvement in neurodegenerative diseases and cognitive impairment. 


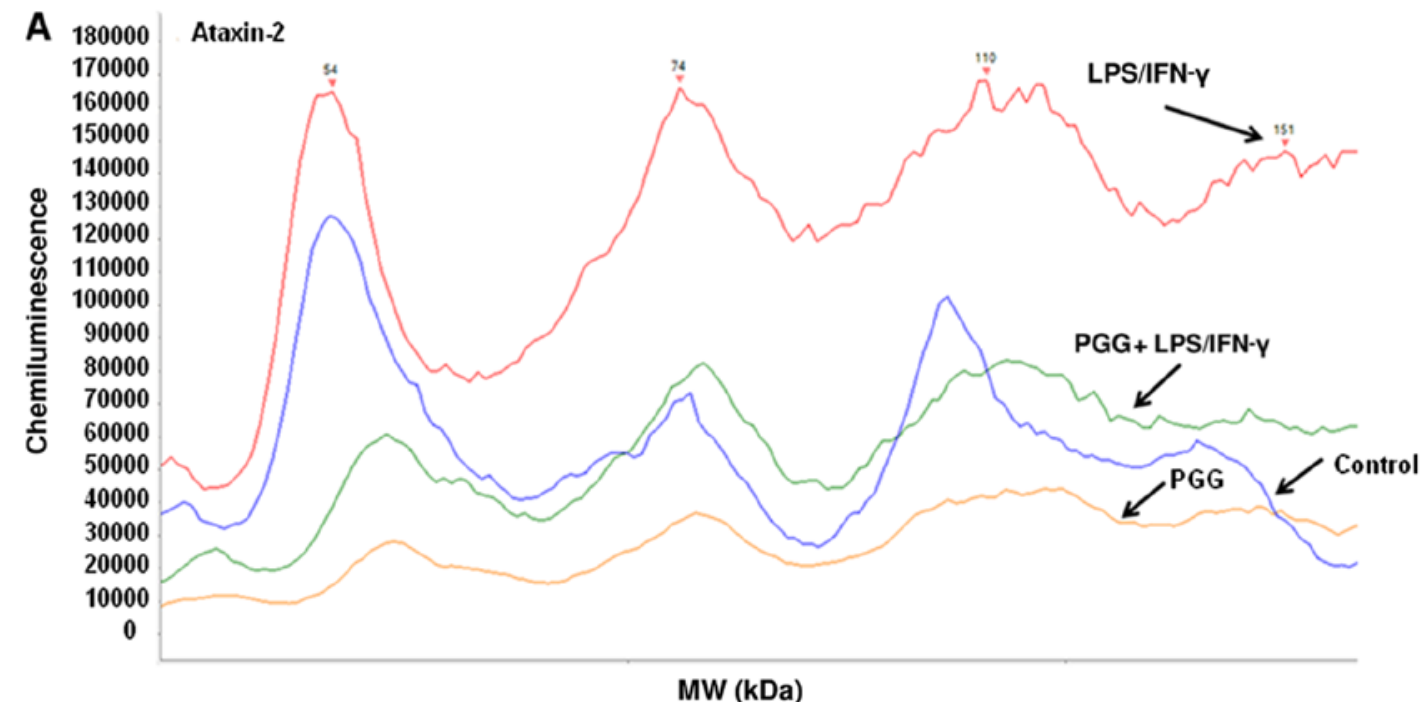

B

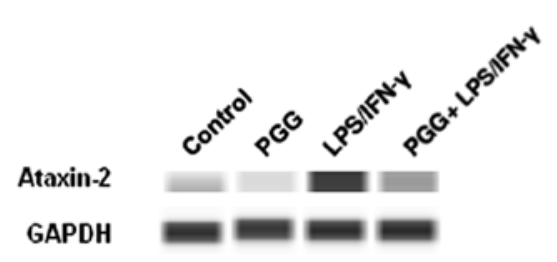

Figure 4. Effect of PGG on the expression of Ataxin-2 as determined by western analysis with automated capillary electrophoresis. (A) Graph of the chemiluminescence levels measured in the different treatment groups. Different peaks represent potential isoforms of the protein, and arrows indicate the peaks corresponding to ataxin-2 (MW: $150 \mathrm{kDa})$. (B) Bands representing the protein expression in control (DMSO), PGG (25 $\mu \mathrm{M}), \mathrm{LPS} / \mathrm{IFN} \gamma$, and pretreated cells $(\mathrm{PGG}+\mathrm{LPS} / \mathrm{IFN} \gamma)$ after $24 \mathrm{~h}$ of treatment $(\mathrm{n}=3)$. PPG, polyphenol pentagalloyl glucose $(1,2,3,4,6$-penta-O-galloyl- $\beta$-D-glucose); LPS, lipopolysaccharide; IFN $\gamma$, interferon $\gamma$; MW, molecular weight.

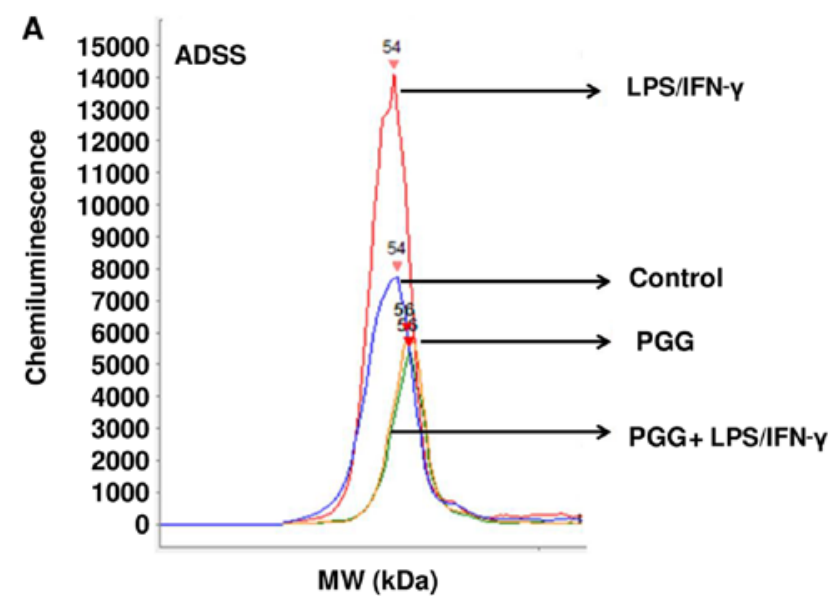

B

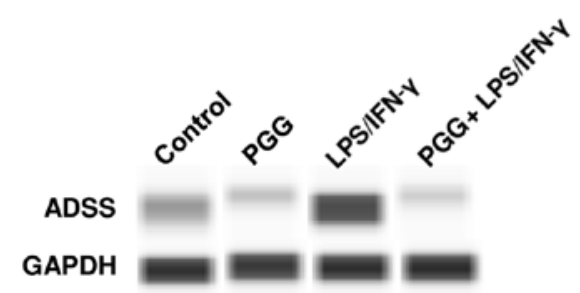

Figure 5. Effect of PGG on the expression of ADSS as determined by western analysis with automated capillary electrophoresis. (A) Graph presenting the chemiluminescence levels measured in the different treatments. (B) shows bands representing the protein expression in control (DMSO), PGG $(25 \mu \mathrm{M}), \mathrm{LPS} / \mathrm{IFN} \gamma$, and pretreated cells $(\mathrm{PGG}+\mathrm{LPS} / \mathrm{IFN} \gamma)$ after $24 \mathrm{~h}$ of treatment $(n=3)$. ADSS, adenylosuccinate synthetase isozyme 2 ; PPG, polyphenol pentagalloyl glucose (1,2,3,4,6-penta-O-galloyl- $\beta$-D-glucose); LPS, lipopolysaccharide; IFN $\gamma$, interferon $\gamma ; \mathrm{MW}$, molecular weight.
Septins may aid in the development of cellular aggregates, although their function in neurodegeneration is still unknown. Additionally, the septin filaments that maintain the structure and shape of the cells become unfolded, which may facilitate the formation of aggregates that interrupt cell function, leading to cell death (29). The septin family provides attractive candidates that may be involved in the essential mechanisms of synaptic dysfunction and neurodegeneration in neurodegenerative diseases. Several reports have described the association of septins with many diseases, including AD, $\mathrm{PD}$, Huntington's disease, frontotemporal lobar degeneration, and Down's syndrome $(26,29,30-35)$, indicating that these proteins are involved in the pathogenic mechanism of neurodegeneration.

Another critical protein whose expression was attenuated by PGG in this study is ataxin 2, which is an RNA-binding protein found in the body with multiple roles in RNA metabolism and is broadly expressed in the mammalian nervous system (36). Ataxin 2 was found to be involved in neurodegenerative diseases, such as amyotrophic lateral sclerosis (ALS) and spinocerebellar ataxia type 2 (SCA2). In mouse models, reduced ataxin 2 levels improved motor performance of the animals in both diseases. In addition, this protein could alter the toxicity produced by the RNA-binding protein TDP43 (encoded by TARDBP), which participates in the formation of aggregates in the brain and spinal cords of ALS patients. A decrease in disease progression was observed when TARDBP transgenic mice were crossed with Atxn2-knockout mice, increasing the median lifespan in $80 \%$ of the animals studied. 

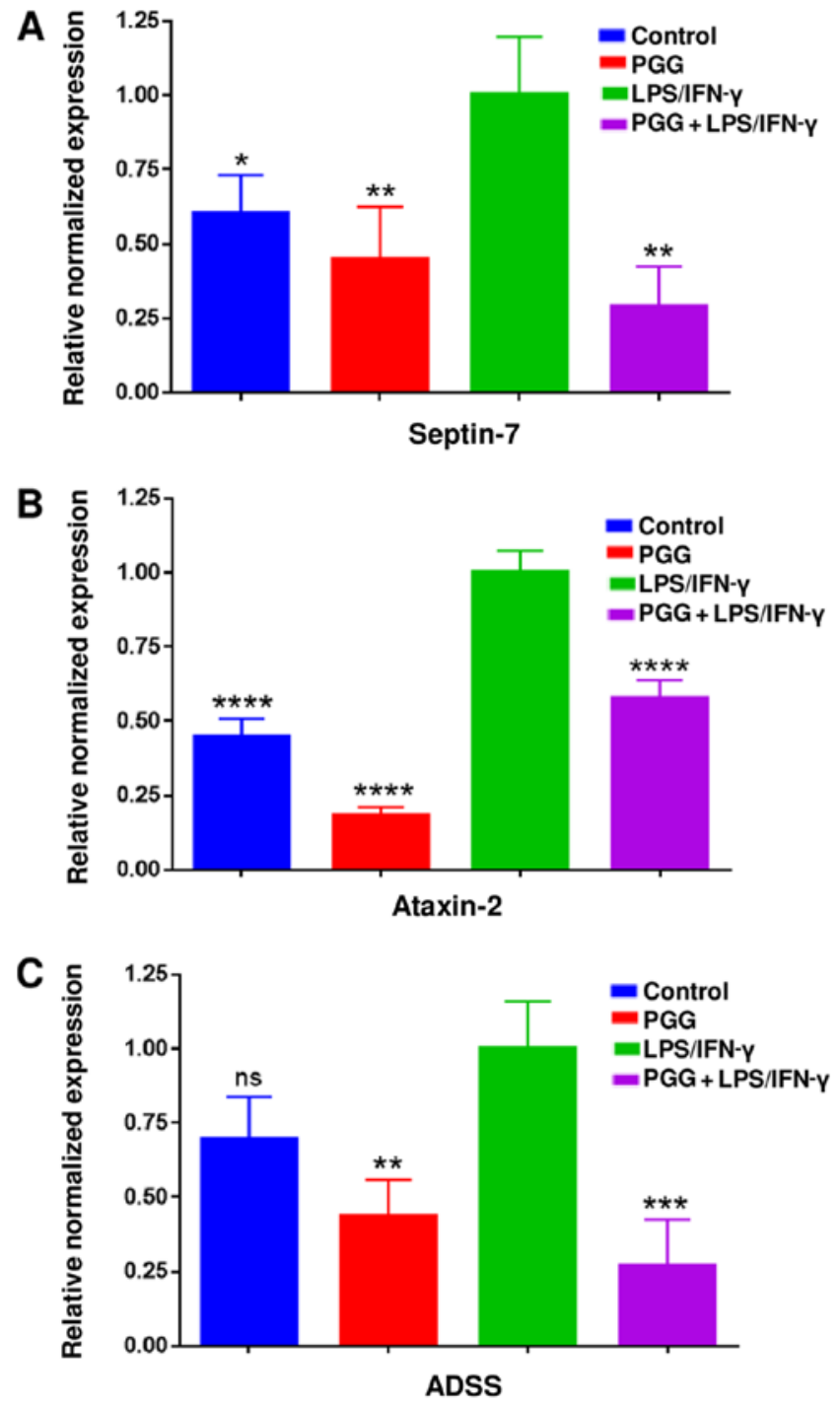

Figure 6. Effect of PGG on mRNA expression of (A) septin-7, (B) ataxin-2 and (C) ADSS using RT-PCR assays. Graphs presenting the changes in the mRNA levels after the different treatments, including control, PGG $(25 \mu \mathrm{M})$, LPS/IFN $\gamma$, and cotreated cells (PGG + LPS/IFN $\gamma$ ). Data represent gene expression presented as the mean \pm standard error of the mean $(n=3)$. ${ }^{*} \mathrm{P}<0.05$, ${ }^{* *} \mathrm{P}<0.01,{ }^{* * *} \mathrm{P}<0.001$ and ${ }^{* * * * *} \mathrm{P}<0.0001$ vs. LPS/IFN $\gamma$. ADSS, adenylosuccinate synthetase isozyme 2; PPG, polyphenol pentagalloyl glucose $(1,2,3,4,6$ penta-O-galloyl- $\beta$-D-glucose); LPS, lipopolysaccharide; IFN $\gamma$, interferon $\gamma$; ns, not significant.

This work suggests that neurodegenerative conditions could be improved by targeting ataxin-2 $(36,37)$.

Furthermore, adenylosuccinate synthetase isozyme 2 (ADSS) was another protein of interest, which was inhibited by PGG in the current study. ADSS is an enzyme that participates in the de novo and salvage pathways for purine and nucleotide biosynthesis, both of which play a role in the formation of nucleotide inosine monophosphate. Vertebrates present two isozymes, one basic (ADSS1) and the other acidic (ADSS2), which respond in a different way to inhibitors, indicating that they differ in their regulation (38-41). The regulation of ADSS is also implicated in the maintenance of AMP/GMP ratios in the cell (38). ADSS was identified as one of the altered proteins in MPTP (1-methyl-4-phenyl-1,2,3,6-tetrahydropyridine)-treated animal models of PD (42). Since mitochondrial dysfunction is likely to be one of the mechanisms that leads to PD, an investigation using quantitative proteomic analysis for mitochondrial protein showed that MPTP-treated animals also presented an increase in the expression of ADSS, from 50 to $100 \%$ (43). The present study, together with previous proteomic studies in the literature, revealed that proteins such as ADSS may be connected to PD pathogenesis and could be regulated by PGG, indicating that this compound may have potential use in targeted therapy.

Since ataxin-2, septin-7 and ADSS were found to be concentrated in neurofibrillary tangles and/or involved in synapse impairment induced by $A \beta$ protein $(26,44)$, these proteins are attractive candidates that may be associated with the fundamental mechanisms of synaptic damage in neurodegenerative diseases. Thus, by inhibiting the expression of these proteins, PGG may provide a useful target compound for neurodegenerative disease therapies.

The proteomic results not only revealed the inhibitory effect of PGG on proteins overexpressed in neurodegenerative diseases but also showed that PGG modulates many proteins involved in different cellular functions, which participate in several signaling pathways. PGG exhibited a significant fold change inhibition in the expression of WAS/WASL-interacting protein family member 1 (WIPF1) (-9.4-fold $\downarrow$ ), thymidylate synthase (-9.7-fold $\downarrow$ ), and glyoxalase (-53-fold $\downarrow$ ), whose overexpression has been shown to be associated with cancer development and progression. The expression of WIPF1 had a critical role in thyroid cancer cell migration and invasion, suggesting WIPF1 as a novel therapeutic target for thyroid cancer (45). Additionally, high levels of thymidylate synthase expression have been correlated with poor prognosis in breast cancer (46), gastric cancer and colorectal cancers $(47,48)$.

In the present study, the most remarkable effect of PGG was on the expression of glyoxalase 4 (GLOD4), with a 53 -fold inhibition. The overexpression of glyoxalases has been reported in numerous types of malignant tumors, such as colon, breast, ovarian, and prostate cancers (49-54). Furthermore, glyoxalases I and II are involved in the detoxification of methylglyoxal, a cytotoxic product of glycolysis, whose overexpression was observed in $79 \%$ of tumors (55). Methylglyoxal and glycation end-products are associated with an increase in proinflammatory markers and affect $A D, A \beta$ peptide depositions and neurofibrillary tangles (56-58). In tumor cells, increased cellular levels of toxic methylglyoxal and $S$-D-lactoylglutathione metabolites are present due to a higher metabolism compared to normal cells. In response to the increase in the production of these cytotoxic products, tumor cells augment the activity of the detoxifying glyoxalase system to minimize the intracellular concentrations of toxic metabolites (59). Methylglyoxal also accumulates with age, and it is associated with age-associated pathologies, such as diabetic complications and neurodegenerative disorders (60). Previous studies using mutant GLOD-4/GLO1-animals (Caenorhabditis elegans model) showed that animals quickly exhibited several pathogenic phenotypes reminiscent of $\alpha$-dicarbonyl stress-induced age-associated disorders (61). Therefore, glyoxalase inhibitors, such as PGG, may have potential as antitumor agents as well as regulatory mediators in neurodegenerative diseases. While the role of glyoxalase 4 is not well established in humans, our results suggest that 
PGG may regulate the expression of distinct but overlapping genes and proteins involved in neurodegeneration and cancer progression.

Although the current study did not directly confirm the effect of PGG on the expression of CDK2, CHUK, IRAK1, and $\mathrm{NF}-\kappa \mathrm{B} 1$ observed in our previous manuscript (13), our current results indirectly showed that there may be an association among all the proteins that were downregulated by PGG. CDK2, CHUK, IRAK1 and NF- $\mathrm{BB} 1$ are proteins involved in the NF- $\kappa \mathrm{B}$ and MAPK signaling pathways, which are both activated by pathogenic and noxious stimuli. Evidence suggests that MAPKs can participate in the regulation of NF- $\kappa \mathrm{B}$ transcriptional activity, demonstrating that both the c-Jun $\mathrm{N}$-terminal kinase and the p38 pathways are implicated in the activation of $\mathrm{NF}-\kappa \mathrm{B}$ in the cytoplasm, as well as in modulation of its transactivation potential in the nucleus, confirming the association between these signaling pathways (62). Moreover, Septin 7 was identified as a novel ERK3-interacting protein by using a Ras recruitment system, and evidence showed that Sept7, ERK3 and MK5 exist in the same complex and, together with Kal7, are of physiological relevance in neuronal plasticity by regulating dendritic spine formation (63). Furthermore, Ataxin-2 was described as a positive regulator of Notch signaling (64), which may maintain NF- $\kappa$ B activity by direct interaction with $\mathrm{p} 50 / \mathrm{c}-\mathrm{Rel}$ in the nucleus (65). Thus, we can conclude that there is an indirect association with the current and previous results due to the overlapping functions and interactions of multiple proteins involved in the NF- $\mathrm{B}$ and MAPK signaling pathways.

The results of this work provide evidence that the polyphenolic compound PGG can modulate the expression of several proteins and transcripts whose expression is increased in LPS/IFN $\gamma$-stimulated BV-2 microglial cells. Among the proteins, PGG significantly inhibited the expression of ataxin-2, septin-7 and ADSS, which play a critical role in synapse impairment and pathogenesis of neurodegenerative diseases. Therefore, this study suggests that PGG may have therapeutic potential for neuroinflammation and neurodegeneration by targeting ataxin-2, septin-7 and ADSS.

\section{Acknowledgements}

Not applicable.

\section{Funding}

The present study was supported by NIH NIMHD (grant nos. G12 MD007582 and P20 MD 006738).

\section{Availability of data and materials}

All data generated or analyzed during this study are included in this published article.

\section{Authors' contributions}

PM and KFAS conceived and designed the study. PM and ET performed the experiments. PM analyzed and interpreted the data, and wrote the manuscript. All authors read and approved the final manuscript.

\section{Ethics approval and consent to participate}

Not applicable.

\section{Patient consent for publication}

Not applicable.

\section{Competing interests}

The authors declare that they have no competing interests.

\section{References}

1. Street WJ, Mark RE and Griffin WS: Microglia and neuroinflammation: A pathological perspective. J Neuroinflammation 1: 14, 2004.

2. Henn A, Lund S, Hedtjärn M, Schrattenholz A, Pörzgen P and Leist M: The suitability of BV-2 cells as an alternative model system for primary microglia cultures for animal experiments examining brain inflammation. ALTEX 26: 83-94, 2009.

3. Schwartz M and Baruch K: The resolution of neuroinflammation in neurodegeneration: Leukocyte recruitment via the choroid plexus. EMBO J 33: 7-22, 2014.

4. Gendelman HE: Neural immunity: Friend or foe? J Neurovirol 8: 474-479, 2002.

5. Oh GS, Pae HO, Choi BM, Lee HS, Kim IK, Yun YG, Kim JD and Chung HT: Penta-O-galloyl-Beta-D-glucose inhibits phorbol myristate acetate-induced interleukin-8 [correction of interleukin-8] gene expression in human monocytic U937 cells through its inactivation of nuclear factor-kappa B. Int Immunopharmacol 4: 377-386, 2004.

6. Hanisch UK: Microglia as a source and target of cytokines. Glia 40: 140-155, 2002.

7. Gao HM and Hong JS: Why neurodegenerative diseases are progressive: Uncontrolled inflammation drives disease progression. Trends Immunol 29: 357-365, 2008.

8. Etminan M, Gill S and Samii A: Effect of non-steroidal anti-inflammatory drugs on risk of Alzheimer's disease: Systematic review and meta-analysis of observational studies. BMJ 327: 128, 2003.

9. McGeer PL and McGeer EG: The amyloid cascade-inflammatory hypothesis of Alzheimer disease: Implications for therapy. Acta Neuropathol 126: 479-497, 2013.

10. Heneka MT, Kummer MP, Weggen S, Bulic B, Multhaup G, Münter L, Hüll M, Pflanzner T and Pietrzik CU: Molecular mechanisms and therapeutic application of NSAIDs and derived compounds in Alzheimer's disease. Curr Alzheimer Res 8: 115-131, 2011.

11. Cao Y, Himmeldirk KB, Qian Y, Ren Y, Malki A and Chen X: Biological and biomedical functions of Penta-O-Galloyl-D-Glucose and its derivatives. J Nat Med 68: 465-472, 2014.

12. Mendonca P, Taka E, Bauer D, Cobourne-Duval $M$ and Soliman KF: The attenuating effects of 1,2,3,4,6 Penta-OGalloyl- $\beta$-D-glucose on inflammatory cytokines release from activated BV-2 microglial cells. J Neuroimmunol 305: 9-15, 2017.

13. Mendonca P, Taka E, Bauer D, Reams RR and Soliman KFA: The attenuating effects of 1,2,3,4,6 penta-O-galloyl- $\beta$-D-glucose on pro-inflammatory responses of LPS/IFN $\gamma$-activated BV-2 microglial cells through NFKB and MAPK signaling pathways. J Neuroimmunol 324: 43-53, 2018.

14. Blasi E, Barluzzi R, Bocchini V, Mazzolla R and Bistoni F: Immortalization of murine microglial cells by a v-raf/v-myc carrying retrovirus. J Neuroimmunol 27: 229-237, 1990.

15. Elsisi N, Darling-Reed S, Lee EY, Oriaku ET and Soliman KF: Ibuprofen and apigenin induce apoptosis and cell cycle arrest in activated microglia. Neurosci Lett 375: 91-96, 2005.

16. NCBI Resource Coordinators: Database resources of the National Center for Biotechnology Information. Nucleic Acids Res 44: D7-D19, 2016.

17. Thomas PD, Campbell MJ, Kejariwal A, Mi H, Karlak B, Daverman R, Diemer K, Muruganujan A and Narechania A: PANTHER: A library of protein families and subfamilies indexed by function. Genome Res 13: 2129-2141, 2003.

18. Amor S, Peferoen LA, Vogel DY, Breur M, van der Valk P, Baker D and van Noort JM: Inflammation in neurodegenerative diseases-an update. Immunology 142: 151-166, 2014. 
19. Abdelwahed A, Bouhlel I, Skandrani I, Valenti K, Kadri M, Guiraud P, Steinman R, Mariotte AM, Ghedira K, Laporte F, et al: Study of antimutagenic and antioxidant activities of Gallic acid and 1,2,3,4,6 penta galloyl glucose from Pistacia lentiscus. Confirmation by microarray expression profiling. Chem Biol Interact 165: 1-13, 2007.

20. Kim BH, Choi MS, Lee HG, Lee SH, Noh KH, Know S, Jeong AJ, Lee H, Yi EH, Park JY, et al: The photoprotective potential of penta-O-galloyl- $\beta$-D-glucose by targeting NF- $\kappa \mathrm{B}$ and MAPK signaling in UVB radiation-induced human dermal fibroblasts and mouse skin. Mol Cells 38: 982-990, 2015.

21. Aithal M and Belur P: Enhancement of propyl gallate yield in a nonaqueous medium using novel cell-associated tannase of Bacillus massiliensis. Prep Biochem Biotechnol 43: 445-455, 2013.

22. Wang KJ, Yang CR and Zhang YJ: Phenolic antioxidants from Chinese toon (fresh young leaves and shoots of Toona sinensis) Food Chemistry 101: 365-371, 2006.

23. Fujiwara H, Tabuchi M, Yamaguchi T, Iwasaki K, Furukawa K, Sekiguchi K, Ikarashi Y, Kudo Y, Higuchi M, Saido TC, et al: Traditional medicinal herb Paeonia suffruticosa and its active constituent 1,2,3,4,6-Penta-O-Galloyl-Beta-D-Glucopyranose have potent anti-aggregation effects on Alzheimer's amyloid beta proteins in vitro and in vivo. J Neurochem 109: 1648-1657, 2009.

24. De Almeida NEC, Do TD, LaPointe NE, Tro M, Feinstein SC, Shea JE and Bowers MT: 1,2,3,4,6-Penta-O-Galloyl- $\beta$-Dglucopyranose binds to the N-terminal metal binding region to inhibit amyloid $\beta$-protein oligomer and fibril formation. Int J Mass Spectrom 420: 24-34, 2017.

25. Stansley B, Post J and Hensley K: A comparative review of cell culture systems for the study of microglial biology in Alzheimer's disease. J Neuroinflammation 9: 115, 2012.

26. Kinoshita A, Kinoshita M, Akiyama H, Tomimoto H, Akiguchi I, Kumar S, Noda M and Kimura J: Identification of septins in neurofibrillary tangles in Alzheimer's disease. Am J Pathol 153 $1551-1560,1998$

27. Tada T, Simonetta A, Batterton M, Kinoshita M, Edbauer D and Sheng M: Role of septin cytoskeleton in spine morphogenesis and dendrite development in neurons. Curr Biol 17: 1752-1758, 2007.

28. Walikonis RS, Jensen ON, Mann M, Provance DW Jr, Mercer JA and Kennedy MB: Identification of proteins in the postsynaptic density fraction by mass spectrometry. J Neurosci 20: 4069-4080, 2000

29. Barr AM, Young CE, Sawada K, Trimble WS, Phillips AG and Honer WG: Abnormalities of presynaptic protein CDCrel-1 in the striatum of rats reared in social isolation: Relevance to neural connectivity in schizophrenia. Eur J Neurosci 20: 303-307, 2004

30. Ageta-Ishihara N, Yamakado H, Morita T, Hattori S, Takao K, Miyakawa T, Takahashi R and Kinoshita M: Chronic overload of SEPT4, a parkin substrate that aggregates in Parkinson's disease, causes behavioral alterations but not neurodegeneration in mice. Mol Brain 6: 35, 2013.

31. Dong Z, Ferger B, Paterna JC, Vogel D, Furler S, Osinde M, Feldon $\mathrm{J}$ and Büeler H: Dopamine-dependent neurodegeneration in rats induced by viral vector-mediated overexpression of the parkin target protein, CDCrel-1. Proc Natl Acad Sci USA 100: 12438-12443, 2003.

32. Gozal YM, Seyfried NT, Gearing M, Glass JD, Heilman CJ, Wuu J, Duong DM, Cheng D, Xia Q, Rees HD, et al: Aberrant septin 11 is associated with sporadic frontotemporal lobar degeneration. Mol Neurodegener 6: 82, 2011.

33. Ihara M, Yamasaki N, Hagiwara A, Tanigaki A, Kitano A, Hikawa R, Tomimoto H, Noda M, Takanashi M, Mori H, et al: Sept4, a component of presynaptic scaffold and Lewy bodies, is required for the suppression of alpha-synuclein neurotoxicity. Neuron 53: 519-533, 2007.

34. Pissuti Damalio JC, Garcia W, Alves Macedo JN, De Almeida Marques I, Andreu JM, Giraldo R, Garratt RC and Ulian Araújo AP: Self-assembly of human septin 2 into amyloid filaments. Biochimie 94: 628-636, 2012

35. Zhang Y, Gao J, Chung KK, Huang H, Dawson VL and Dawson TM: Parkin functions as an E2-dependent ubiquitinprotein ligase and promotes the degradation of the synaptic vesicle-associated protein, CDCrel-1. Proc Natl Acad Sci USA 97: 13354-13359, 2000 .

36. Crunkhorn S: Neurodegenerative disorders: Ataxin 2 reduction rescues motor defects. Nat Rev Drug Discov 16: 384-385, 2017.

37. Schmidt EE, Pelz O, Buhlmann S, Kerr G, Horn T and Boutros M: RNAi: A database for cell-based and in vivo RNAi phenotypes, 2013 update. Nucleic Acids Res 41: D1021-D1026, 2013.
38. Stayton MM, Rudolph FB and Fromm HJ: Regulation, genetics, and properties of adenylosuccinate synthetase. Curr Top Cell Regul 22: 103-141, 1983 .

39. Borza T, Iancu CV, Pike E, Honzatko RB and Fromm HJ: Variations in the response of mouse isozymes of adenylosuccinate synthetase to inhibitors of physiological relevance. J Biol Chem 278: 6673-6679, 2003.

40. Oshchepkova-Nedosekina EA and Likhoshvai VA: A mathematical model for the adenylosuccinate synthetase reaction involved in purine biosynthesis. Theor Biol Med Model 4: 11, 2007.

41. Nomura Y, Nozawa A and Tozawa Y: Biochemical analyses of ppGpp effect on adenylosuccinate synthetases, key enzymes in purine biosynthesis in rice. Biosci Biotechnol Biochem 78 1022-1025, 2014

42. Sowell RA, Owen JB and Butterfield DA: Proteomics in animal models of Alzheimer's and Parkinson's diseases. Ageing Res Rev 8: 1-17, 2009.

43. Jin J, Meredith GE, Chen L, Zhou Y, Xu J, Shie FS, Lockhart P and Zhang J: Quantitative proteomic analysis of mitochondrial proteins: Relevance to Lewy body formation and Parkinson's disease. Brain Res. Mol. Brain Res 134: 119-138, 2005.

44. Wan W, Xia S, Kalionis B, Liu L and Li Y: The role of Wnt signaling in the development of Alzheimer's disease: A potential therapeutic target? Biomed Res Int 2014: 301575, 2014.

45. Zhang T, Shen X, Liu R, Zhu G, Bishop J and Xing M Epigenetically upregulated WIPF1 plays a major role in BRAF V600E-promoted papillary thyroid cancer aggressiveness. Oncotarget 8: 900-914, 2017.

46. Pestalozzi BC, Peterson HF, Gelber RD, Goldhirsch A, Gusterson BA, Trihia H, Lindtner J, Cortés-Funes H, Simmoncini E, Byrne MJ, et al: Prognostic importance of thymidylate synthase expression in early breast cancer. J Clin Oncol 15: 1923-1931, 1997.

47. Johnston PG, Lenz HJ, Leichman CG, Danenberg KD, Allegra CJ, Danenberg PV and Leichman L: Thymidylate synthase gene and protein expression correlate and are associated with response to 5 -fluorouracil in human colorectal and gastric tumors. Cancer Res 55: 1407-1412, 1995.

48. Nimmagadda S and Shields AF: The role of DNA synthesis imaging in cancer in the era of targeted therapeutics. Cancer Metastasis Rev 27: 575-587, 2008

49. Ranganathan S and Tew KD: Analysis of Glyoxalase-I from normal and tumor tissue from human colon. Biochim Biophys Acta 1182: 311-316, 1993

50. Ranganathan S, Walsh ES and Tew KD: Glyoxalase I in detoxification: Studies using glyoxalase I transfectant cell line. Biochem J 309: 127-131, 1995.

51. Rulli A, Carli L, Romani R, Baroni T, Giovannini E, Rosi G and Talesa V: Expression of glyoxalase I and II in normal and breast cancer tissues. Breast Cancer Res Treat 66: 67-72, 2001

52. Jones MB, Krutzsch H, Shu H, Zhao Y, Liotta LA, Kohn EC and Petricoin EF III: Proteomic analysis and identification of new biomarkers and therapeutic targets for invasive ovarian cancer. Proteomics 2: 76-84, 2002.

53. Di Ilio C, Angelucci S, Pennelli A, Zezza A, Tenaglia R and Sacchetta P: Glyoxalase activities in tumor and non-tumor human urogenital tissues. Cancer Lett 96: 189-193, 1995.

54. Davidson SD, Cherry JP, Choudhury MS, Tazaki H, Mallouh C and Konno S: Glyoxalase I activity in human prostate cancer: A potential marker and importance in chemotherapy. J Urol 161: 690-691, 1999.

55. Fonseca-Sánchez MA, Rodríguez-Cuevas S, MendozaHernández G, Bautista-Piña V, Arechaga Ocampo E, Hidalgo Miranda A, Quintanar Jurado V, Marchat LA, Alvarez-Sánchez E, Pérez Plasencia C and López-Camarillo C: Breast cancer proteomics reveals a positive correlation between glyoxalase 1 expression and high tumor grade. Int $\mathbf{J}$ Oncol 41: 670-680, 2012.

56. Ledesma MD, Bonay P and Avila J: Tau protein from Alzheimer's disease patients is glycated at its tubulin-binding domain. J Neurochem 65: 1658-1664, 1995.

57. Vitek MP, Bhattacharya K, Glendening JM, Stopa E, Vlassara H, Bucala R, Manogue K and Cerami A: Advanced glycation end products contribute to amyloidosis in Alzheimer disease. Proc Natl Acad Sci USA 91: 4766-4770, 1994.

58. Angeloni C, Zambonin L and Hrelia S: Role of methylglyoxal in Alzheimer's disease. Biomed Res Int 2014: 238485, 2014.

59. Al-Balas QA, Hassan MA, Al-Shar'i NA, Mhaidat NM, Almaaytah AM, Al-Mahasneh FM and Isawi IH: Novel glyoxalase-I inhibitors possessing a 'zinc-binding feature' as potential anticancer agents. Drug Des Devel Ther 10: 2623-2629, 2016. 
60. Thornalley PJ: Methylglyoxal, glyoxalases and the development of diabetic complications. Amino Acids 6: 15-23, 1994.

61. Chaudhuri J, Bose N, Gong J, Hall D, Rifkind A, Bhaumik D, Peiris TH, Chamoli M,LeCH,Liu J,etal: A Caenorhabditis elegans model elucidates a conserved role for TRPA1-Nrf signaling in reactive $\alpha$-Dicarbonyl detoxification. Curr Biol 26: 3014-3025, 2016.

62. Schulze-Osthoff K, Ferrari D, Riehemann K and Wesselborg S: Regulation of NF-kappa B activation by MAP kinase cascades. Immunobiology 198: 35-49, 1997.

63. Brand F, Schumacher S, Kant S, Menon MB, Simon R, Turgeon B, Britsch S, Meloche S, Gaestel M and Kotlyarov A: The extracellular signal-regulated kinase 3 (mitogen-activated protein kinase 6 [MAPK6])-MAPK-activated protein kinase 5 signaling complex regulates septin function and dendrite morphology. Mol Cell Biol 32: 2467-2478, 2012.
64. Shukla JP, Deshpande G and Shashidhara LS: Ataxin 2-binding protein 1 is a context-specific positive regulator of Notch signaling during neurogenesis in Drosophila melanogaster. Development 144: 905-915, 2017.

65. Shin HM, Minter LM, Cho OH, Gottipati S, Fauq AH, Golde TE, Sonenshein GE and Osborne BA: Notch1 augments NF-kappaB activity by facilitating its nuclear retention. EMBO J 25: 129-138, 2006.

This work is licensed under a Creative Commons Attribution-NonCommercial-NoDerivatives 4.0 International (CC BY-NC-ND 4.0) License. 